\title{
Incidental cardiac findings on computed tomography imaging of the thorax
}

Paul WX Foley', Ali Hamaad', Hossam El-Gendi', Francisco Leyva2²

\begin{abstract}
Background: Investigation of pulmonary pathology with computed tomography also allows visualisation of the heart and major vessels. We sought to explore whether clinically relevant cardiac pathology could be identified on computed tomography pulmonary angiograms (CTPA) requested for the exclusion of pulmonary embolism (PE). 100 consecutive CT contrast-enhanced pulmonary angiograms carried out for exclusion of PE at a single centre were assessed retrospectively by two cardiologists.

Findings: Evidence of PE was reported in 5\% of scans. Incidental cardiac findings included: aortic wall calcification (54\%), coronary calcification (46\%), cardiomegaly (41\%), atrial dilatation (18\%), mitral annulus calcification (15\%), right ventricular dilatation (11\%), aortic dilatation (8\%) and right ventricular thrombus (1\%). Apart from 3 (3\%) reports describing cardiomegaly, no other cardiac findings were described in radiologists' reports. Other reported pulmonary abnormalities included: lung nodules (14\%), lobar collapse/consolidation (8\%), pleural effusion (2\%), lobar collapse/consolidation (8\%), emphysema (6\%) and pleural calcification (4\%).

Conclusions: CTPAs requested for the exclusion of PE have a high yield of cardiac abnormalities. Although these abnormalities may not have implications for acute clinical management, they may, nevertheless, be important in long-term care.
\end{abstract}

\section{Introduction}

Computed tomography pulmonary angiography (CTPA) has become a first line investigation for suspected pulmonary embolism (PE) [1-3]. Although primarily geared towards visualisation of the lungs, currently available CTPA also provides images of the heart. Incidental lung findings, such as benign and malignant nodules, can be found in patients undergoing cardiovascular magnetic resonance (CMR) [4] and cardiac CT [5-8]. We sought to determine the frequency cardiac abnormalities in patients undergoing CTPA for suspected PE.

\section{Methods}

One hundred consecutive patients aged 64 (19) (mean [SD]) underwent CTPA in the period April to July 2007. The scans, acquired on a non-gated conventional 16slice CT scanner (Philips Brilliance scanner, city, country) using bolus tracking, were analysed retrospectively

\footnotetext{
* Correspondence: cardiologists@hotmail.com

${ }^{2}$ Centre for Cardiovascular Sciences, Queen Elizabeth Hospital, University of Birmingham, UK

Full list of author information is available at the end of the article
}

and independently by two cardiologists (AH, PWXF). Any disagreements in findings were referred to a third cardiologist (HEG) with Level 2 cardiac CT accreditation. These reports were compared with previously issued radiological reports. Both atrial and ventricular dimensions were made in the transverse plane at the mid-ventricular level.

\section{Statistical analysis}

Absolute numbers of findings for each type of pathology was converted into a percentage of the total number of scans analysed.

\section{Results}

\section{Pulmonary abnormalities}

As shown in Table 1, 5\% of scans revealed evidence of PE. Additional pulmonary abnormalities included: lung nodules (14\%), lobar collapse/consolidation (8\%), emphysema (6\%), pleural effusion (2\%) and pleural calcification (4\%). This amounted to $39 \%$ of scans showing pulmonary abnormalities. 
Table 1 Summary of incidental cardiac findings on 100 CT scans requested for the diagnosis of possible pulmonary embolism (\%)

\begin{tabular}{ll}
\hline Pulmonary findings & $\mathbf{3 9}$ \\
\hline Lung nodules & 14 \\
Lobar collapse/consolidation & 8 \\
Emphysema & 6 \\
Pulmonary embolism & 5 \\
Pleural disease & 4 \\
Pleural effusion & 2 \\
Cardiac findings & \\
Aortic wall calcification & 54 \\
Coronary calcification & 46 \\
Cardiomegaly (CTR > 1:2) & 41 \\
Bi-ventricular dilatation & 16 \\
Left ventricular dilatation & 14 \\
Right ventricular dilation & 11 \\
Atrial dilatation & 18 \\
Mitral annulus calcification & 15 \\
Aortic dilatation & 8 \\
Intracardiac thrombus & 1 \\
\hline
\end{tabular}

\section{Cardiac abnormalities}

According to the retrospective report from cardiologists, $78 \%$ of scans had at least one incidental cardiac finding (Table 1). According to the previous radiological reports, only 3 contained a reference to a cardiac finding namely, 3 cases of cardiomegaly. Figure 1 illustrates some examples of incidental cardiac findings.

\section{Discussion}

Computed tomography pulmonary angiography has become a routine investigation for the investigation of acute PE. The British Thoracic Society and European Society of Cardiology guidelines recommend the use of CTPA as the initial investigation method of choice in non-massive PE [9]. In this consecutive series of patients admitted as an emergency for the exclusion of PE, only $5 \%$ of CTPAs yielded evidence of PE. Importantly, however, cardiac abnormalities were evident in $78 \%$ of scans. Prominent amongst these were coronary and aortic wall calcification, and cardiomegaly. Less frequent findings included atrial dilatation and calcification of the aortic valve and/or mitral annulus.
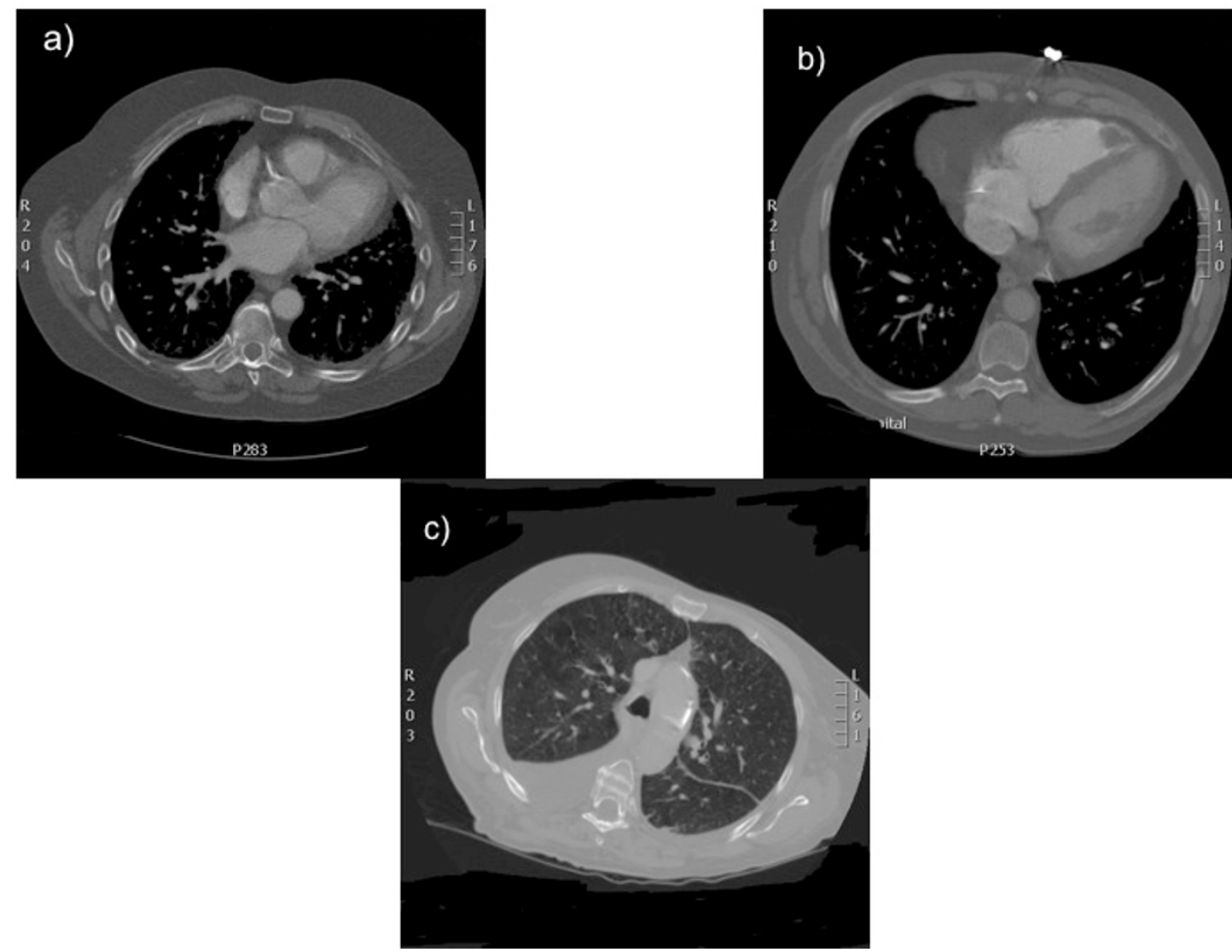

Figure 1 Examples of incidental findings observed on CT pulmonary angiograms. Figure 1a: coronary calcification, Figure $1 \mathrm{~b}$ : right ventricular mural thrombus. Figure 1c: aortic wall calcification. 
Although incidental cardiac findings may not be relevant to the immediate clinical management of patients with suspected PE, they may nevertheless influence long-term clinical management. For example, coronary and aortic wall calcification are markers of atherosclerosis $[10,11]$. According to several studies of asymptomatic individuals with subclinical atherosclerosis, treatment with statins, [12-14] and aspirin [15-17] improve atherosclerotic burden and prolongs survival. Reporting of these cardiac findings may therefore influence primary prevention of atherosclerotic events. Cardiomegaly, on the other hand, is a late feature of left ventricular dysfunction and heart failure [18], both of which carry a very poor prognosis [19]. Inclusion of such incidental findings on thoracic CTPA reports could therefore trigger further cardiac investigations and treatment. Failure to report cardiovascular pathology in CT scans has been recently highlighted in a study of aortic root dilatation in the Veteran Affairs Health Care System [20].

We conclude that thoracic CT scans frequently yield evidence of incidental cardiovascular pathology. Whilst these findings may not be relevant to immediate clinical management, they may well be clinically relevant in the long-term. Radiologists' reports of thoracic CT scans should therefore include cardiac findings.

\section{Key messages}

1. Incidental cardiac findings of significant pathology are common on CT scans of the thorax.

2. Reporting of cardiac abnormalities is important as potentially management may be changed as a result

3. Cardiac abnormalities are more common than pulmonary emboli on CT scans

4. Cardiac failure is associated with cardiomegaly. The presence of cardiomegaly should prompt further cardiac investigation.

5. Incidental cardiac findings are usually not reported.

\section{Author details}

${ }^{1}$ Department of Cardiology, University of Birmingham, Good Hope Hospital, Sutton Coldfield, West Midlands, B72 1JW, UK. ${ }^{2}$ Centre for Cardiovascular Sciences, Queen Elizabeth Hospital, University of Birmingham, UK.

\section{Authors' contributions}

$\mathrm{AH}$ and PWXF analysed the scans together and wrote the manuscript. HEG arbitrated where there was dispute in the findings and contributed to the manuscript. FL inspired the study and as senior author re-wrote parts of the manuscript. All authors have read and approved the final manuscript.

\section{Competing interests}

The authors declare that they have no competing interests.

Received: 30 June 2010 Accepted: 3 December 2010 Published: 3 December 2010
References

1. Garg K, Welsh CH, Feyerabend AJ, Subber SW, Russ PD, Johnston RJ, et al: Pulmonary embolism: diagnosis with spiral CT and ventilation-perfusion scanning - correlation with pulmonary angiographic results or clinical outcome. Radiology 1998, 208:201-208.

2. Perrier A, Howarth N, Didier D, Loubeyre P, Unger PF, de Moerloose P, et al: Performance of helical computed tomography in unselected outpatients with suspected pulmonary embolism. Ann Intern Med 2001, 135:88-97.

3. Mayo JR, Remy-Jardin M, Müller NL, Remy J, Worsley DF, Hossein-Foucher C, et al: Pulmonary embolism: prospective comparison of spiral CT with ventilation-perfusion scintigraphy. Radiology 1997, 205:447-452.

4. David AM, Monish L, Patrick MC: The prevalence of incidental findings at cardiac MRI. Open Cardiovasc Med J 2008, 2:20-25.

5. Aglan I, Jodocy D, Hiehs S, Soegner P, Frank R, Haberfellner B, et al: Clinical relevance and scope of accidental extracoronary findings in coronary computed tomography angiography: A cardiac versus thoracic FOV study. Eur J Radiol 2009.

6. Iribarren C, Hlatky MA, Chandra M, Fair JM, Rubin GD, Go AS, et al: Incidental pulmonary nodules on cardiac computed tomography: prognosis and use. Am J Med 2008, 121:989-996.

7. Kim JW, Kang EY, Yong HS, Kim YK, Woo OH, Oh YW, et al: Incidental extracardiac findings at cardiac CT angiography: comparison of prevalence and clinical significance between pre-contrast low-dose whole thoracic scan and post-contrast retrospective ECG-gated cardiac scan. Int J Cardiovasc Imaging 2009, 25(Suppl 1):75-81.

8. Kirsch J, Araoz PA, Steinberg FB, Fletcher JG, McCollough CH, Williamson EE: Prevalence and significance of incidental extracardiac findings at 64multidetector coronary CTA. J Thorac Imaging 2007, 22:330-334.

9. British Thoracic Society Standards of Care Committee PE Guideline Development Group: British Thoracic Society guidelines for the management of suspected acute PE. Thorax 2003, 58:470-483.

10. Greenland P, La Bree L, Azen SP, Doherty TM, Detrano RC: Coronary artery calcium score combined with Framingham risk score for risk prediction in asymptomatic individuals. JAMA 2004, 291:210-215.

11. LaMonte MJ, FitzGerald SJ, Church TS, Barlow CE, Radford NB, Levine BD, et al: Coronary artery calcium score and coronary heart disease events in a large cohort of asymptomatic men and women. Am J Epidemiol 2005, 162:421-429.

12. Smilde TJ, van Wissen S, Wollersheim H, Trip MD, Kastelein JJ, Stalenhoef AF: Effect of aggressive versus conventional lipid lowering on atherosclerosis progression in familial hypercholesterolemia (ASAP): a prospective, randomized, double-blind trial. Lancet 2001, 357:577-81.

13. Kastelein JJ, Sager PT, de Groot E, Veltri E: Comparison of ezetimibe plus simvastatin versus simvastatin monotherapy on atherosclerosis progression in familial hypercholesterolemia: design and rationale of the Ezetimibe and Simvastatin in Hypercholesterolemia Enhances Atherosclerosis Regression (ENHANCE) trial. Am Heart J 2005, 149:234-9.

14. Crouse JR III, Raichlen JS, Riley WA, for the METEOR Study Group, et al: Effect of rosuvastatin on progression of carotid intima-media thickness in low-risk individuals with subclinical atherosclerosis: the METEOR trial. JAMA 2007, 297:1344-53.

15. Peto R, Gray R, Collins R, Wheatley K, Hennekens C, Jamrozik K, Warlow C, Hafner B, Thompson E, Norton S, Gilliland J, Doll R: Randomised trial of prophylactic daily aspirin in British male doctors. Br Med J (Clin Res Ed) 1988, 296:313-316.

16. Final report on the aspirin component of the ongoing Physicians' Health Study: Steering Committee of the Physicians' Health Study Research Group. N Engl J Med 1989, 321:129-135.

17. Eidelman RS, Hebert PR, Weisman SM, Hennekens $\mathrm{CH}$ : An update on aspirin in the primary prevention of cardiovascular disease. Arch Intern Med 2003, 163:2006-2010.

18. Goldberg LR, Jessup M: Stage B heart failure. Circulation 2006, 113:2851-2860.

19. Schocken DD, Benjamin EJ, Fonarow GC, Krumholz HM, Levy D, Mensah GA, et al: Prevention of heart failure: A Scientific Statement From the American Heart Association Councils on Epidemiology and Prevention, Clinical Cardiology, Cardiovascular Nursing, and High Blood Pressure Research; Quality of Care and Outcomes Research Interdisciplinary Working Group; and Functional Genomics and Translational Biology Interdisciplinary Working Group. Circulation 2008, 117:2544-2565. 
20. Gordon JR, Wahls T, Carlos RC, Pipinos II, Rosenthal GE, Cram P: Failure to Recognize Newly Identified Aortic Dilations in a Health Care System With an Advanced Electronic Medical Record. Ann Intern Med 2009, 151:21-7, W5.

doi:10.1186/1756-0500-3-326

Cite this article as: Foley et al:: Incidental cardiac findings on computed tomography imaging of the thorax. BMC Research Notes 2010 3:326.

Submit your next manuscript to BioMed Central and take full advantage of:

- Convenient online submission

- Thorough peer review

- No space constraints or color figure charges

- Immediate publication on acceptance

- Inclusion in PubMed, CAS, Scopus and Google Scholar

- Research which is freely available for redistribution

Submit your manuscript at www.biomedcentral.com/submit
C Biomed Central 